\title{
Genetic polymorphisms associated with the development and clinical course of multiple sclerosis (Review)
}

\author{
ANA PAULA KALLAUR ${ }^{1}$, DAMACIO RAMÓN KAIMEN-MACIEL ${ }^{2,3}$, \\ HELENA KAMINAMI MORIMOTO ${ }^{4}$, MARIA ANGELICA EHARA WATANABE ${ }^{5}$, \\ SÉRGIO MURILO GEORGETO ${ }^{2}$ and EDNA MARIA VISSOCI REICHE ${ }^{4}$
}

${ }^{1}$ Health Sciences Postgraduation Program, Health Sciences Center, ${ }^{2}$ Department of Clinical Medicine, Health Sciences Center, ${ }^{3}$ Outpatient Clinic for Multiple Sclerosis, Health Sciences Center, ${ }^{4}$ Department of Pathology, Clinical Analysis and Toxicology, Health Sciences Center, ${ }^{5}$ Department of Pathological

Sciences, Biological Sciences Center, State University of Londrina, Londrina, Parana, Brazil

Received February 22, 2011; Accepted April 8, 2011

DOI: 10.3892/ijmm.2011.731

\begin{abstract}
Multiple sclerosis (MS) is an autoimmune disease characterized by areas of inflammation, demyelination and axonal damage. The etiology of MS is multifactorial with an interaction between genetic, environmental and geographical factors. The objective of this study was to review the physiopathology and the genetic polymorphisms associated with the development and clinical course of MS. Studies carried out in populations worldwide showed that polymorphisms in the genes of the major histocompatibility complex (MHC) class II and class III have been associated with susceptibility, resistance and clinical forms of MS. Considerable attention has been focused on studies evaluating disease-modifying effects in MS that identified seven genes of probable importance such as the HLA class II, ApoE, IL-1ra, IL-1 $\beta$, TNF- $\alpha$, TNF- $\beta$ and CCR5 genes. However, the results described in the literature about genetic biomarkers in MS are not consistent in the worldwide population. The detection of a single nucleotide polymorphism involved in the etiology and physiopathology of MS is very difficult and, it is likely that, several genetic polymorphisms are involved, each with a small contribution to the susceptibility or resistance to MS. Taken together the results show the need for continued research in genetically heterogeneous populations to identify new biomarkers associated with MS that could be used as prognostic markers or as therapeutic targets to modulate the autoimmune response in MS patients. This information may contribute to a better understanding of the physiopathology and treatment of MS,
\end{abstract}

Correspondence to: Dr Edna Maria Vissoci Reiche, Department of Pathology, Clinical Analysis and Toxicology, Health Sciences Center, State University of Londrina, Av. Robert Koch 60, CEP 86.038-440, Londrina, Parana, Brazil

E-mail: reiche@sercomtel.com.br

Key words: multiple sclerosis, genetic polymorphism, tumor necrosis factor $\alpha$, tumor necrosis factor $\beta$, major histocompatibility complex with the possibility of developing different therapeutic strategies according to the genetic profile of each individual.

\section{Contents}

1. Introduction

2. Study design

3. The physiopathology of MS

4. Genetic polymorphisms and MS in the worldwide population

5. Genetic polymorphism and MS in the Brazilian population

6. Final considerations

\section{Introduction}

Multiple sclerosis (MS) is a chronic disorder of the central nervous system (CNS) characterized by an autoimmune response directed against myelin proteins and other unidentified antigens, resulting in demyelination and dense astrogliosis in the white substance of the CNS. Clinically, MS is characterized by episodes of focal disorders of the optic nerves, trunk, periventricular region, spinal cord and cerebellum, with remission of a variable magnitude and relapse in a period of many years. The clinical manifestations are vague, being determined by the location and extent of the demyelination (1-3).

Several clinical forms of MS have been identified, such as the relapsing-remitting (RR-MS), the secondary progressive (SP-MS), the primary progressive (PP-MS) and the benign forms (4-6). Approximately $80 \%$ of the patients will initially present the RR-MS form, in which there are unpredictable attacks (remission), appearance of new symptoms or increased severity existing symptoms. SP-MS is characterized by progression that is not relapse-related. PP-MS affects around 10-15\% of all MS patients and is characterized by a lack of distinct attacks, but with slow onset and then steadily worsening symptoms. There is an accumulation of deficits and disability, which may level off at some point or continue over the years. 
The diagnosis of a benign form MS is retrospective when the accumulated disability from RR-MS is either mild or non-existent after a long period (usually considered to be 15-20 years) (7).

RR-MS and SP-MS may together be considered as aboutonset disease, as ultimately the majority of patients with RR-MS develop a secondary progressive course (8). However, the interval between the onset of the disease and the beginning of the secondary progressive course may be influenced by genetic factors. Genetic markers predicting this interval could be pertinent to decisions about early institution of long-term immune modulation therapy protocols.

In addition to the broad clinical spectrum of the MS, there is also heterogeneity in the morphological alterations of the brain identified by magnetic resonance imaging (MRI) or by histopathological evaluation, as well as in the clinical presentation, e.g. in the response to therapy and in which CNS system and areas are primarily affected (9-11). The 2005 revisions to the McDonald diagnostic criteria for MS, with the use of imaging and cerebrospinal fluid (CSF) findings, introduced important changes, simplifying and speeding diagnosis, while maintaining adequate sensitivity and specificity $(5,7,12)$. MS severity can be evaluated by assessing the levels of inflammatory biomarkers and of demyelination observed in MRI with gadolinium-enhancing imaging, and by the Expanded Disability Status Scale of Kurtzke (EDSS). A positive MRI gadolinium-enhancement indicates an ongoing inflammation and activity of the MS process, whereas a gadolinium-negative imaging should be considered as a sign of stabilization of the MS process (13).

The age of onset has a unimodal distribution with a peak between 20 and 30 years and the symptoms are rarely initiated before 10 or after 60 years. The MS incidence is $\sim 2$ or 3-fold higher in women than men and in patients with late onset, the rate seems to equalize $(1,14-17)$. Epidemiological studies suggest that MS etiology is multifactorial with a complex interaction between environmental factors, such as infectious agents, and genetic factors (14). Autoimmune mechanisms and viral infections may also have a pathogenic role in MS $(1,2,7)$. Evidence is mounting that genetic variation influences not only the susceptibility to MS, but also the clinical course and severity (18).

Correlation studies of the racial differences in the prevalence rates of worldwide MS, reveals that the Caucasian population appears to have a high risk whereas the Asian population similarly to Blacks have a lower risk. Epidemiologic studies suggest that MS susceptibility is hereditary and the risk for developing the disease is 15-fold higher when MS is present in a first-degree relative. Studies with families and twins provide good support for the genetic susceptibility. In high prevalence areas, the risk of developing MS is $0.00125 \%$ in the general population. Siblings of patients with MS have a risk of $\sim 2.6 \%$, parents have a risk of $1.8 \%$ and sons have a risk of $\sim 1.5 \%$. Overall, about $15 \%$ of the patients with MS have an affected relative. Study data with twins indicate a concordance of $25 \%$ in monozygotic twins and only $2.4 \%$ in dizygotic twins with the same gender $(1,7,16)$.

As a complex disease, MS susceptibility is probably conferred to multiple genes. Data from family lineages with more than one affected member are consistent with the hypothesis that multiple non-correlated genes are associated with susceptibility to MS. The major histocompatibility complex (MHC), located on the short arm of human chromosome 6, is considered as a genetic determinant in MS. At the MHC region, the human leukocyte antigen (HLA) genes encode important molecules involved in the immune response. Of the three classes of HLA genes, the strongest MS association occurs with class II alleles $(1,7,16)$.

Several genetic polymorphisms previously described in different populations worlwide have been associated with the susceptibility, resistance and outcome of MS. However, contradictory results are reported in the literature when a genetically different population is evaluated. The aim of this study was to conduct a review on polymorphisms in genes that encode molecules involved in the physiopathology, the development and the heterogeneity of the clinical course of MS in the worldwide population.

\section{Study design}

Information was selected and obtained from virtual database such as Medline and PubMed, including references, abstracts and full text of journal articles in Portugese and English, published between 1972 and 2011. Keywords and descriptors of health were used in association with MS, genetic polymorphism, tumor necrosis factor, lymphotoxin- $\alpha$, HLA alleles and MHC genes.

\section{The physiopathology of MS}

MS is considered to be an autoimmune disorder mediated by activated $\mathrm{CD}^{+}{ }^{+} \mathrm{T}$ helper lymphocytes that recognize the major autoantigens, such as the myelin basic protein (MBP), proteolipidic protein (PLP), myelin oligodendrocytic protein (MOG) and the myelin-associated glycoprotein (MAG).Adisproportional number of activated $\mathrm{CD} 4^{+} \mathrm{T}$ cells was found in MS lesions and it is not clear whether these cells play a primary role in the initial events and lead to the destruction of myelin or if they trigger the events that occur inside or outside of the CNS (14).

The activation of autoreactive $\mathrm{CD} 4^{+} \mathrm{T}$ cells and their differentiation into a Th1 phenotype is an important event in the initial stages of the disease, and these cells are probably also important players in the long-term evolution of the disease. However, the damage of the target tissue, the CNS, is most likely mediated by other components of the immune system, such as antibodies, complement components, $\mathrm{CD} 8^{+} \mathrm{T}$ cells, and factors produced by innate immune cells. Perturbations in immunomodulatory networks that include, mainly, Th2 cells, regulatory $\mathrm{CD}^{+}{ }^{+} \mathrm{T}$ cells, natural killer (NK) cells may in part be responsible for the relapsing-remitting or chronic progressive nature of the MS (14).

Myelin-specific $\mathrm{CD}^{+} \mathrm{T}$ cells are thought to initiate and, in cooperation with $\mathrm{B}$ cells, perpetuate the immune processes of the disease. Both elimination of $\mathrm{T}$ cells and damage to the CNS by immune cells are central pathogenic mechanisms of MS. It seems likely that apoptosis plays a central role in both of these processes (19). While elimination of T cells by apoptosis is a physiological control mechanism, tissue damage in the CNS is a physiopathological feature. Tumor necrosis factor (TNF)- $\alpha$, CD95 (Apo-1/Fas) ligand, and other ligands, such as the TNF-related apoptosis inducing ligand (TRAIL or Apo-2 
ligand) interact with their respective receptors to induce apoptotic cell death. Similar to the CD95 ligand (CD95L) and TNF- $\alpha$, surface bound and soluble TRAIL were shown to rapidly induce apoptosis in susceptible tumor cells upon trimerization of its receptors and subsequent activation of the caspases cascade, leading to fragmentation of DNA (20). TRAIL is able to induce massive neuronal cell destruction in the human brain (21). Since TRAIL receptors, but not the ligand, are expressed in the normal human brain and human antigen-specific $\mathrm{T}$ cells upon activation up-regulate TRAIL, this system is expected to have a role in neuroinflammation. Blockade of TRAIL expressed in $\mathrm{CD}^{+}$myelin-specific $\mathrm{T}$ cells reduces caspase-dependent neuronal cell death and markedly ameliorates clinical severity in experimental autoimmune encephalomyelitis, an animal model for MS (22).

MS demyelination leads to an axonal block. Some cytokines may play a role in the conduction block, particularly the pro-inflammatory cytokines TNF- $\alpha$, and TNF- $\beta$, and interferon- $\gamma($ IFN- $\gamma)$. Cytokines have indirect effects on neural function and direct effects on ion channels, but clear and direct effects on axonal conduction have been difficult to detect. On the other hand, TNF- $\alpha$ and IFN- $\gamma$ are potent in stimulating the formation of the inducible form of the nitric oxide synthase (iNOS) enzyme and it can produce nitric oxide (NO) sustained and in high concentration. Theoretically, inflammation also contributes to neurological deficits by modifying the properties of glial cells, particularly, astrocytes and microglia $(23,24)$.

The biological activities of chemokines are mediated by interactions with their corresponding chemokine receptors and they are involved in the pathogenesis of immune-mediated inflammation of the CNS, both in controlling leukocyte migration across brain endothelium and in the activation and movement of cells within the brain parenchyma. During a variety of inflammatory and degenerative conditions, glial cells within the CNS have the capacity to express chemokines, such as CCL2 (previously named monocyte chemoattractant protein-1 or MCP-1), CCL3 (previously named macrophage inflammatory protein-1 $\alpha$, MIP-1 $\alpha$ ), CCL4 (previously named MIP-1 $\beta$ ), and CCL5 (previously named regulated upon activation protein normally T-cell expressed and secreted, RANTES). Glial cells also express the CC chemokines receptors (CCR) such as CCR2, CCR4, CCR5 and CXC receptors (CXCR). The preferential expression of CCR5 and CXCR3 occurs in $\mathrm{CD} 4^{+}$Th1 cells, and the expression of CCR3 and CCR4 in $\mathrm{CD} 4^{+} \mathrm{Th} 2$ cells. The profile of chemokine receptors on $\mathrm{CD} 4^{+}$ Th1 may, in part, explain the selective recruitment of the $\mathrm{T}$ cell subpopulation to the sites of inflammation, including the predominance of CD $4^{+}$Th1 cells, expressing CCR5 and CXCR3 in MS lesions. By contrast, CCR2 is up-regulated in activated T cells, and is also present in mononuclear phagocytes (25). Different pairs of chemokine receptors and their ligands seem to play a pathogenic role in MS, such as the receptor CXCR 3 and its ligands CXCL9 and CXCL10; CCR1 and CCL3, CCL4 and CCL5; CCR2 and CCL2; CCR5 and CCL3, CCL4 and CCL5. Interfering with the chemokine system may be an effective therapeutic approach in MS (26).

Four patterns of demyelination have been described in early active MS lesions suggesting that discrete pathways may lead to the common endpoint of myelin injury in MS (11). All four patterns share the infiltration of macrophages and T-cells. The most common patterns, types I and II, are characterized by sharp lesion borders that surround blood vessels, oligodendrocyte survival and remyelination, and suggest a primary inflammation mechanism of myelin injury. Pattern II is distinguished from pattern I by immunoglobulin deposition and complement activation in regions of active myelin destruction. Patterns I and II resemble autoimmune experimental models of MS and suggest myelin as the target of injury. In contrast, patterns III and IV show very little remyelination due to depletion of oligodendrocytes. Pattern III is further distinguished by preferential loss of MAG, apoptotic oligodendrocytes, and features consisting of a distal, dying-back oligodendrogliopathy with degeneration of the inner glial loop. Pattern IV lesions demonstrate degeneration of oligodendrocytes in the periplaque white matter preceding demyelination. These patterns resemble toxic, viral and/or ischemic models of MS, and suggest that oligodendrocytes may be the targets of injury (27).

All four patterns co-express CCR1 and CCR5. In pattern II lesions, the number of CCR1-expressing cells is decreased, while the number of CCR5-expressing cells is increased in late active vs. active regions. In contrast, $\mathrm{CCR} 1^{+}$and $\mathrm{CCR}^{+} \mathrm{T}$ cells were equal in all regions of pattern III lesions. These suggest distinct inflammatory microenvironments in pattern II and III lesions and support MS pathological heterogeneity and that CCR5 expression could modulate patterns I and II but not patterns III and IV pathology (27).

A significant increase in surface expression of CCR5 in $\mathrm{CD}^{+}, \mathrm{CD}^{+}, \mathrm{CD} 9^{+}$and $\mathrm{CD} 14^{+}$cells as well as an increased percentage of CXCR3 and CXCR4 in $\mathrm{CD} 14^{+}$cells was found in MS patients compared to controls. Increased levels of CXCL10 (IP-10) and CCL5 (RANTES) in CSF were also observed in a subgroup of MS patients. These results support that chemokines and their receptors are involved in the pathogenesis of MS $(28,29)$.

A role for the CXCL12 (previously named stromal cell derived factor 1 or SDF1- $\alpha$ ) in the pathogenesis of MS was also evaluated (30). This chemokine is constitutively expressed at low levels in the CNS and is essential in CNS development. It is also chemoattractant for resting and activated T cells, as well as monocytes. Immunohistochemical analysis of chronic active and chronic silent MS lesions was performed to evaluate CXCL12 expression. In active MS lesions, CXCL12 levels were high on astrocytes throughout lesion areas and on some monocytes/macrophages within vessels and perivascular cuffs, with low staining in endothelial cells. In silent MS lesions, CXCL12 stainning was lower than that observed in active MS lesions, and was also detected in endothelial cells and astrocytes, particularly hypertrophic astrocytes near the lesion edge. The endothelial cells expressed CXCR4, the receptor for CXCL12, suggesting that this chemokine may activate endothelial cells to produce other mediators involved in MS and may initiate and increase the inflammatory response during MS.

Due to the importance of inflammatory cells inside and around of MS plaques and the immune mechanisms that affect myelin distribution, these factors have been largely studied. In the allergic encephalomyelitis, an experimental model of MS, the inflammation and demyelination are seen after animal immunization with myelin, myelin protein and other peptides 
of this protein. The experimental disturbance can be adoptively transferred by encephalitogenic $\mathrm{CD}^{+} \mathrm{T}$ cells into a naive animal. The plaques infiltrating around the brain contain $\mathrm{CD}^{+} \mathrm{T}$ and $\mathrm{CD} 4^{+} \mathrm{T}$ cells and macrophage. It is believed that macrophage and $T$ cells induce damage in the oligodendrocytes. It was suggested that $\mathrm{CD}^{+} \mathrm{T}$ cytotoxic cells use Fas/FasL due to that oligodendrocytes express Fas, whereas FasL is present in infiltrated T cells. However, a variety of studies demonstrated that factors other than cellular immunity are needed for the development of similar MS lesions $(16,31)$.

\section{Genetic polymorphisms and MS in the worldwide population}

Cytokines and their receptor genes. Polymorphisms in genes that code cytokine and their receptors have been associated with the susceptibility or resistance to various infectious or autoimmune diseases, and to clinical disease variables, including MS. However, there is still no definitive evidence of such association (32).

Interleukin-1 $\beta$ (IL-1 $\beta)$ and $I L-1$ receptor antagonist (IL-1RA) genes. IL-1 $\beta$ and IL-1RA genes, which exert opposing functions in the immune system and which are in linkage disequilibrium over an extraordinary distance of $360 \mathrm{~kb}$ (33), have been studied as disease modifying candidate genes in MS. Association of a single nucleotide polymorphism (SNP) in exon 5 (E5) of IL-1 $\beta$ with disease severity has been demonstrated in two studies utilizing different methods to correct for disease duration by assessing time-dependent disability $(33,34)$. In both of these studies, allele 2 of the IL-1 $\beta$ E5, which is associated with higher expression of IL-1 $\beta$, is found to be independently associated with a favorable prognosis in MS. Studies on another SNP in the promoter region of the IL-1 $\beta$ gene $(-511)$, have yielded conflicting results $(35,36)$.

A variable number of an 85 -base pair tandem repeat (VNTR) in intron-4 of the IL-1ra gene has also been studied. The presence of allele 2 has been associated with higher expression of the protein and was found to be an independent and favorable prognostic factor in four studies (27). However, other studies did not confirm this result $(33,34)$. The lack of association in these latter studies could be due to the fact that the population in these studies is ethnically distinct from that in the other studies. It may also be due the differences in the outcome analysis. Larger-scale studies and formal metaanalysis are needed to confirm the disease modifying effects observed for IL-1 $\beta$ and IL-1ra polymorphisms (27).

Interleukin-10 (IL-10) gene. IL-10 is an anti-inflammatory cytokine which may modulate disease expression in MS. The dimorphic functional polymorphisms within the IL-10 promoter region at positions $-1082,-819$ and -519 has been previously investigated for their possible influence on the susceptibility and outcome of MS. Specifically, a polymorphism at the IL-10 promoter gene located at position -1082 results in two alleles, named $-1082 \mathrm{~A}$ and $-1082 \mathrm{G}$, that have been associated with low and high in vitro IL-10 production, respectively. When evaluated in healthy individuals compared to MS patients from a population with different genetic background and severity of disease, the results were contradictory. Several studies do not show any association with MS, nor with the progression related to patients' disability (37-39). The same polymorphism was evaluated in MS patients and healthy subjects from Finland in order to investigate the influence on the susceptibility and outcome of MS. Although the $A \rightarrow G$ substitution at position -1082 on the IL-10 gene proved to be protective against $\mathrm{MS}$ in all patients (OR, 0.32), the effect increased over the years (10 years, OR, 0.33; 15 years, OR, 0.21 ; 20 years, OR, 0.14) demonstrating that it is not associated with MS susceptibility. The authors suggest that differential production of IL-10 might be a factor in the severity of MS (40).

IL-10 expression is related to the polymorphisms -1082 $(\mathrm{G} \rightarrow \mathrm{A}),-819(\mathrm{~T} \rightarrow \mathrm{C})$ and $-592(\mathrm{~A} \rightarrow \mathrm{C})$ in the promoter region of the IL-10 gene, which constitute three haplotypes, GCC, ATA and ACC. The ATA (a non-GCC) haplotype, which is associated with low IL-10 expression, was analyzed to determine whether it could influence the initial interferon (IFN) treatment response in RR-MS patients from Norway. During the first six months of treatment, MS patients with non-GCC haplotypes experienced fewer new MRI T1-contrast enhancing lesions than patients with the GCC haplotype. However, no differences were detected in the clinical disease activity suggesting an influence of the IL-10 promoter polymorphism on the IFN treatment response in MS (41).

Interleukin 2 (IL-2) and the $I L-2$ receptor $(I L-2 R)$ genes. IL-2 and IL-2R signaling promotes proliferation and survival of activated $\mathrm{CD}^{+} \mathrm{T}$ cells and has an essential non-redundant role in the production of regulatory $\mathrm{T}$ cells (Treg). A recent transversal study and meta-analysis of IL-2 and the IL-2R antagonist (IL-2RA) were evaluated in an MS patient from Madrid (Spain) and the results confirmed the association of polymorphisms in the IL-2RA gene with susceptibility in this MS population (42).

TNF- $a$, TNF- $\beta$ and the TNF receptor genes. Both TNF- $\alpha$ and TNF- $\beta$ (also named Linfotoxin- $\alpha$ or LTa) genes are located on the HLA class III region. Studies of the TNF region are of particular interest because TNF- $\alpha$ and TNF- $\beta$ are tandemly located within the HLA complex, suggesting that these genes may be in linkage disequilibrium with the HLA-DR loci that are associated with MS (27). Previous allelic association studies in Northern Ireland using microsatellite markers (a, b, c and d) localized within a $20-\mathrm{kb}$ region around the TNF genes have shown significantly different allele distributions of the TNFa and $b$ markers betwen MS patients and controls (43).

TNF- $\alpha$ is a pluripotent pro-inflammatory cytokine secreted mainly by macrophages and $\mathrm{CD} 4^{+} \mathrm{Th} 1$ cells. TNF- $\alpha$ modulates the immune response by induction of MHC class II antigens, adhesion molecule expression and dysfunction of the bloodbrain barrier. The first step in the induction of many of the biological effects elicited by TNF- $\alpha$ is its binding to cell surface receptors. TNF receptors (TNFR) have been detected in a variety of normal tissues and cell lines either sensitive or resistant to TNF. Two distinct receptors, a 55-60 kDa (TNFRI) and a 75-80 kDa (TNFRII), have been identified, and both are able to neutralize circulating TNF- $\alpha$ (44).

Several studies have indicated that $\mathrm{TNF}-\alpha$ is a critical pro-inflammatory cytotoxic cytokine and immunopathogenetic mediator in MS. Increased expression of TNF- $\alpha$ has been 
shown to be associated with clinical activity in RR-MS and the development of chronic progressive disease. TNF- $\alpha$ induces a wide variety of responses including apoptotic cell death, enhanced ischemic and excitotoxic injury in neurons, but also neuroprotection (45). The co-existence of neurotoxic and neuroprotective effects of TNF- $\alpha$ may be partially explained by two different signaling pathways mediated by the two cellsurface receptors, TNFRI and TNFRII. In vivo studies have demonstrated that TNFRI mainly mediates CNS inflammation and demyelination, whereas TNFRII enhances remyelination. Both receptors have also been shown to exist in soluble forms and are thereby able to neutralize circulating TNF- $\alpha$. Serum and CSF concentration of the soluble forms of both receptors have been shown to correlate with the clinical activity in MS patients. These findings have encouraged researchers to investigate genetic variants of the TNFRII gene and its association with the susceptibility to and clinical progression of MS (44).

The interindividual variation in the capacity to produce TNF- $\alpha$ may be caused by differences in either transcription rate, the regulation of mRNA stability, translation efficiency or processing of the mature protein. Polymorphisms in the genes encoding proteins that regulate this process may cause differences in TNF- $\alpha$ production. Different polymorphisms have been described in the promoter TNF- $\alpha$ gene, such as the SNP at position -308 of the TNF- $\alpha$ promoter, which consists of a substitution of a $\mathrm{G}$ (TNF1 allele, more common) to an A (TNF2 allele, less common) (46,47). The TNF2 allele has been associated with higher constitutive and inducible levels of TNF gene transcription as compared to the wild-type genotype. It has been also shown that this SNP is associated with increased $\mathrm{TNF}-\alpha$ production in in vitro stimulation. Therefore, this genetic variation may result in altered TNF- $\alpha$ expression and thereby affects the susceptibility and clinical severity of inflammatory diseases (47). However, contradictory results have also been reported. In one study, the TNF2 allele did not correlate with the increased number of TNF- $\alpha$ expressing cells, indicating that the consistently observed increase of TNF- $\alpha$ production in MS by a variety of assays is better explained by the number of TNF- $\alpha$ expressing cells, than by a functionally relevant promoter polymorphism (48).

A study carried out in the Netherlands examined TNF- $\alpha$ levels and the distribution of the polymorphisms $-308,-238$ and -376 in the promoter of the TNF- $\alpha$ gene. Increased TNF- $\alpha$ levels in the CSF were detected in patients with active MS compared to healthy individuals. In MS patients, the level of TNF- $\alpha$ produced by peripheral blood mononuclear cells was correlated with the extent of neurological deterioration and disability. Therefore, the distribution of -238 and -308 polymorphisms were tested in two different groups of MS patients. In MS patients with severe neurological disability that needed hospitalization, the $-238 \mathrm{~A}$ allele was not detected. In MS outpatients, the frequency of the $-238 \mathrm{G}$ allele was higher, but not significantly different from the controls. The -308 genotypes were not differently distributed in patients compared to controls both in the first and the second group of MS patients, suggesting that the $-238 \mathrm{G} \rightarrow \mathrm{A}$ transition polymorphism in the TNF- $\alpha$ promoter is less common in MS patients with neurological damage. It may be possible that the $-238 \mathrm{~A}$ allele is protective against damage in MS, while it is not associated with differences in susceptibility (46). Another study showed no significant differences in the TNF- $\alpha-238$ and -308 promoter polymorphisms evaluated in French MS patients and in healthy individuals (49).

The exon 3 variant of the TNF- $\beta$ or LTa gene leads to a substitution at amino acid position 26 (aspartate to threonine), and correlates with a reduced level of TNF- $\beta$ production. Another TNF- $\beta$ gene polymorphism identified by restriction fragment length polymorphism (RFLP) using the restriction enzyme $N c o$ I (named the NcoI TNF- $\beta$ polymorphism) resides within intron 1 , has been described as being correlated with the exon 3 polymorphism and affects TNF- $\beta$ gene expression levels (50). The combination of these allelic forms may lead to different levels of cytokine production in response to various physiological and pathological stimuli and in turn may result in a predisposition to the development of MS or a different clinical status of MS (23). The association of TNF- $\alpha$ and TNF- $\beta$ allelic polymorphism frequency with the occurrence and clinical type and severity of MS was evaluated in a Polish Caucasian population. Both point mutations (-308 promoter of TNF- $\alpha$ gene and exon 3 TNF- $\beta$ gene) seem to be inherited independently, since no difference was found between the number of the combined allelic types and the expected number calculated by the multiplication of the separated frequencies for TNF- $\alpha$ and TNF- $\beta$ alleles in both control and MS patients. The frequency of the $-308 \mathrm{G} \rightarrow \mathrm{A}$ mutation in the TNF- $\alpha$ promoter region in normal controls was $15.0 \%$ and $24.0 \%$ in MS. For the TNF- $\beta$ gene the exon 3 polymorphism allele A was detected in $36.0 \%$ of controls and $34.0 \%$ of MS patients. In MS, the combined genotype TNF- $\alpha \mathrm{G}$ and TNF- $\beta \mathrm{C}+\mathrm{C}$ was present six times more frequently $(12.0 \%)$ than in controls (2.0\%), and the patients with this genotype showed the highest EDSS scores. Other combinations did not show a difference between the MS and non-MS groups. Both mutations are related with higher cytokine production; however, no statistical difference was observed between TNF- $\alpha$ and TNF- $\beta$ levels (23).

In a different study the TNF- $\alpha-308$ polymorphism was evaluated in 283 MS patients from Germany, in 72 patients with amyotrophic lateral sclerosis (ALS) and 66 patients with stroke, all of them from the same genetic background who served as controls. Disease severity was defined by the progression index and by the EDSS. Of the 283 MS patients, $67.0 \%$ were homozygous for the TNF1 allele, $28.0 \%$ were heterozygous for the TNF2 allele, and 3.0\% were homozygous for the TNF2 allele. No significant differences were found between the TNF2 allelic frequency in the group of patients with MS, ALS and stroke. In a subgroup of 87 MS patients with stable disease, $30.0 \%$ with the TNF2 allele and $70 \%$ without TNF2 allele, a quantitative polymerase chain reaction (PCR) was performed to determine TNF- $\alpha$ mRNA baseline levels and the results did not show an association between the presence of the TNF2 allele and the clinical course of MS. The investigators concluded that the TNF2 allele, as a genetic marker, itself, does not significantly contribute to the severity of MS. They suggested that primary factors other than variations in the TNF- $\alpha$ promoter region could contribute to MS susceptibility and disease progression. Nevertheless, functional differences in the -308 polymorphism were demonstrated because increased TNF- $\alpha$ mRNA levels were detected in patients carrying the TNF2 allele. There is no doubt that 
TNF- $\alpha$ is found in MS lesions, up-regulated prior to relapses, and can cause oligodendrocyte damage and demyelination. However, increased basal production of this cytokine, associated with the TNF2 allele, may not be relevant for disease susceptibility or progression (47).

A significant correlation was also found between MS susceptibility and the TNF- $\alpha-376$ promoter polymorphism, when it was evaluated in 238 MS patients and in 324 control subjects from Spain. This association was independent of the HLA class II association and the combined inheritance of HLA-DRB1*1501 and the TNF- $\alpha-376$ A allele more than additively increased the susceptibility to MS (51).

The TNF- $\alpha-308$ polymorphism, in which the rare TNF2 allele is associated with high TNF- $\alpha$ production, was also evaluated in 143 unrelated Serbian patients with MS and 123 ethnically matched, healthy individuals using allele-specific RFLP-PCR. The frequency of the TNF2 allele was significantly decreased in MS patients (14.0\%) in comparison to the controls $(24.0 \%, \mathrm{P}=0.044)$. However, the TNF2 allele had no influence on disease behavior, since it was not associated with the course and severity of MS in this group of patients, suggesting that in the Serbian population, polymorphism at position -308 of TNF- $\alpha$ or at an adjacent locus may have a role in MS susceptibility (52).

An association between the TNF- $\alpha$ 376A promoter polymorphism and the susceptibility to MS was found in the Spanish population, but not in other populations. Two distinct datasets of patients and control subjects were enrolled to confirm this result suggesting that this association is specific to the Spanish white (or related) population or, alternatively, that only studies in this population have adequate statistical power because of the higher frequency of an extended, conserved haplotype carrying the TNF- $\alpha$ 376A allele (53).

Genetic association studies have been performed to evaluate the role of TNFRI and TNFRII in MS. In one study, no association was found between microsatellite markers in the TNFRI and TNFRII genes and MS (44). Another study, investigating polymorphisms in the TNFRI gene in MS patients using RFLP, found almost no genetic variation in the coding region and no association with disease course or severity (54).

No significant differences were observed in the frequency of two polymorphisms from the TNFRI gene (located in exon 1 and intron 6) evaluated in 94 Jewish Ashkenazi MS patients and 83 healthy Ashkenazi controls (55). This finding suggests that genetic variants in TNFRI do not play a significant role in Ashkenazi Jews. However, the size sample could limit the validity of the results obtained.

Polymorphic sites in exon 6 and and exon 10 of the TNFRII gene were evaluated in MS patients and controls. The detection of a SNP in exon 6, position 783 with a $G \rightarrow A$ substitution, evaluated in a Caucasian population, resulted in a non-conserved amino acid substitution of a glutamic acid (GAA) for a lysine (AAA). Other SNPs were also confirmed in exon 6 , position 676 with a $T \rightarrow G$ substitution, resulting in a substitution of a methionine for an arginine; on exon 10 with a $\mathrm{G} \rightarrow \mathrm{A}$ substitution; on exon 10 position 1668 with a $\mathrm{T} \rightarrow \mathrm{G}$ substitution and on exon 10 position 1690 with a $\mathrm{T} \rightarrow \mathrm{C}$ substitution, which result in no amino acid substitutions because they are located downstream of the stop codon. There were no significant differences in the allele frequencies and genotype distribution of SNPs in the TNFRII gene between MS patients and control, with the exception of one in exon 10, position 1668 with a $\mathrm{T} \rightarrow \mathrm{G}$ substitution polymorphism. In MS patients, $2.5 \%$ were positive for the $1668^{*} \mathrm{G}$ allele, whereas $5.5 \%$ were positive in the healthy control group $(\mathrm{P}=0.019)$. Genotype analysis revealed that the lower frequency of the $1668^{*} \mathrm{G}$ allele in MS patients was caused by an increased in the proportion of $1668^{*} \mathrm{~T} / \mathrm{T}$ homozygous patients. However, the differences in the $1668^{*} \mathrm{~T} \rightarrow \mathrm{G}$ polymorphism between patients and control may indicate that TNFRII contributes to overall MS susceptibility. When RR-MS and SP-MS patients were compared to those with PP-MS, no difference in genotype and phenotype frequencies were found. The data also showed that there was no association between genotype and carrier status of any polymorphism and gender, age, age at onset, EDSS, disease duration, and number of relapses in MS patients (56).

Chemokines and their receptors genes. Most chemokine genes are encoded in a cluster on chromosome 17q11.2-12, which has been identified in a number of genome-wide screens as being potentially associated with MS. The CCL5, CCL3 and CCL4 ligands use the same receptor CCR5 that has been implicated in the pathogenesis of MS. CCR5 is present mainly in cells of the immune system, such as macrophages and T lymphocytes and plays a major role in the migration of these cells to sites of inflammation. The gene encoding CCR5 is located in the p21.3 region of the human chromosome 3 forming a cluster with other chemokine receptor genes (57). In previous reports, high levels of all of the ligands of CCR5 (CCL2, CCL3, CCL4 and CCL5), were detected in chronic active MS lesions (58), underscoring the role of CCR5 in the pathogenesis of MS. It thus appears that the CCR5 genetic polymorphisms are of particular interest in MS.

The deletion of 32 base pairs in the CCR5 gene, named CCR 5- $\Delta 32$, results in a truncated protein and in failure to express the receptor on the cell surface. It was demonstrated that $15.0-20.0 \%$ of Caucasian individuals were heterozygous for the CCR5- $\triangle 32$ allele and $1.0 \%$ or less was homozygous for this variant allele (59). Further studies demonstrated that the CCR $5-\Delta 32$ allele was present in $\sim 10.0 \%$ of the European descendants, was rarely observed in Asia and was virtually absent in the native population from sub-Saharan Africa (57,60-62). A study of the allelic frequency of CCR5- $\Delta 32$ in 18 European populations revealed an interesting north-south gradient, with the highest frequencies of the variant allele being observed in the Finnish and Modrvinian populations (16.0\%) and the lowest in Sardinia (4.0\%) (63).

Several studies investigating the role of the CCR5- $\Delta 32$ polymorphism in MS have reported varied, often contradictory results. Whether the CCR 5- $\Delta 32$ allele could influence the inflammatory response in MS was evaluated in 68 patients with possible onset symptoms of MS and 80 patients with an attack of RR-MS. CD4 ${ }^{+} \mathrm{T}$ cell activation and commonly used measures of immune activation in MS such as intrathecal immunoglobulin synthesis, CSF leukocyte count, MMP-9 activity, and the CSF concentration of neopterin were measured. In this study, the homozygosity frequency for the CCR5- $\Delta 32$ allele was comparable in MS patients and controls and the age, gender, EDSS score, disease duration, and other variables evaluated did not differ in patients carrying the CCR5- $\Delta 32$ 
and patients carrying the normal CCR5 alleles. However, data from a prospective 1-year follow-up study demonstrated that patients carrying the CCR5- $\Delta 32$ had a lower risk of recurrent disease activity than the patients with normal CCR5 alleles, and the onset of chronic progression was only observed in patients with wild-type CCR5 alleles, suggesting that treatment targeting CCR5 inhibitors may attenuate disease activity in MS (64).

The chromosome 3p21-24 region was examined in 125 MS families (322 total affected and 200 affected sib-pairs) and genetic analysis of CCR5 and CCR2B loci and two nearby markers (D3S1289 and D3S1300) was performed using both linkage-and association-based tests. The results showed no evidence of linkage to MS for any of the tested markers. Affected relative-pair and sib-pair analysis, and association testing for each locus were also not significant. However, age of onset was approximately three years later in patients carrying the CCR5- $\Delta 32$ deletion $(\mathrm{P}=0.018$ after controlling for gender effects), suggesting that CCR5 expression may be associated with differential disease onset in a subset of MS patients, and may provide a therapeutic target to modulate inflammatory demyelination (65).

The association between the CCR5- $\Delta 32$ deletion and disease progression measured by clinical disability and MRI parameters was evaluated in a population-based patient sample $(n=70)$. Patients with the CCR5- $\triangle 32$ allele showed a non-significant trend towards a small lesion burden (total lesion area/years duration), but the presence of this allele was not associated with a mild EDSS/year duration. The data support the previous hypothesis of a modulation of severity in MS by the CCR5- $\triangle 32$ genotype, which may result in less inflammation and tissue destruction (66). However, due the limited number of patients enrolled, weak associations between this polymorphism and disease variables cannot be excluded. When 256 MS patients from Israel were evaluated, the progression to disability was prolonged in MS patients carrying the CCR5- $\Delta 32$ allele (homozygote and heterozygote genotypes for variant allele) compared with MS patients carrying the CCR5 wild-type genotype, suggesting that this variant allele may have favorable prognostic implications in MS (67).

Contradictory results have also been reported. A group of 120 unrelated Australian RR-MS patients and 168 unrelated control subjects were screened for the CCR5- $\Delta 32$ deletion. There was no significant difference in the allele frequency between the MS patients and the control group. The presence of two CCR 5- $\Delta 32$ homozygotes in the MS patients may indicate that the absence of CCR5 is not protective against MS and that CCR5 is not an essential component in MS, though this may be due to a redundancy in the chemokine system with different chemokine receptors substituting for CCR5 when it is absent (68).

A study evaluating DNA isolated from postmortem brain tissue samples of 132 MS patients and from blood tissue samples of 163 gender and ethnicity-matched healthy controls was used to screen for the CCR5- $\Delta 32$ allele (69). An increased frequency of CCR5- $\triangle 32$ was found to be associated with early death and with a progressive reduction in the years of survival. The death hazard ratio of CCR5- $\Delta 32$ vs. the CCR 5 allele was 2.12 (3.58 for female patients), suggesting that MS patients carrying the CCR5- $\triangle 32$ allele have twice the mortality rate of patients with wild-type genotype. Conflicting data with previous studies showing an association between CCR5- $\Delta 32$ carriage and a better prognosis of MS have been reported. No significant difference in the distribution of the CCR5- $\Delta 32$ allele was observed between $331 \mathrm{RR} / \mathrm{SP}-\mathrm{MS}$ patients and controls, between the 108 PP-MS patients and controls or between the PP-MS and RR/SP-MS groups. Furthermore, no differences in the rate of disease progression were detected between carriers and non-carriers of the CCR5- $\Delta 32$ allele. In the populationbased group of RR/SP-MS patients, carriage of the CCR5- $\Delta 32$ polymorphism was associated with a lower age at disease onset (mean age 26.562 vs. 31.065 years). However, significant differences in the age of onset were also present in the PP-MS group or in a second RR-MS population, suggesting that the CCR $5-\Delta 32$ polymorphism is not a major determinant of susceptibility to MS (70).

In a study of the worldwide population, individuals who had the CCR5- $\Delta 32$ allelic variant presented lower MS activity and severity (32). The CCR5- $\Delta 32$ polymorphism was evaluated in 221 MS patients, and revealed that $75.6 \%$ of them had the wild-type genotype, $23.5 \%$ were heterozygous and $0.9 \%$ was homozygous for the CCR5- $\Delta 32$ allele. There was no association between the genotype or the presence of the CCR5- $\Delta 32$ allele and the disease and its severity, age of onset of MS and gender. The frequency of genotypes observed in 94 patients with biopsy-derived, pathologically confirmed demyelinating disease was $81.9 \%$ wild-type, $16.0 \%$ heterozygous and $2.1 \%$ homozygous for the CCR5- $\Delta 32$ allele, similar to the frequency distribution in the population-based sample. No association between the genotype or carrier status for CCR5- $\Delta 32$ with the immunopathological classification of MS was observed. Although the results were not significant, the major differences in CCR5 expression in pattern II compared with pattern III MS lesion, may reflect differences in the pathogenic stimulus trigger and/ or inflammatory microenvironment, rather than a genetic effect related to the CCR5 gene (27). This study suggests that CCR5 is unnecessary for the recruitment of $\mathrm{CD} 4^{+} \mathrm{T}$ cells or macrophages to the CNS in MS, but CCR5-induced lymphocyte activation may be transduced by this receptor. Dependent CCR5 effector functions of mononuclear phagocytes may also be affected. This study has important pharmacogenomic implications considering that CCR5- $\Delta 32$ may influence the response to treatment by leading to low CCR5 levels.

The association of the CCR $5-\Delta 32$ allele with the risk of/or disease processes in Croatian and Slovenian MS patients was evaluated. A total of 325 MS patients and 356 healthy controls were genotyped by PCR and the results showed no significant differences in the distribution of the CCR $5-\Delta 32$ allele between the individuals, indicating that this allele does not influence susceptibility to MS. Furthermore, the study found that the CCR5- $\Delta 32$ carrier-status could not modulate age of disease onset or progression of the disease, suggesting that the CCR5$\Delta 32$ is neither protective, nor a risk factor, for MS development (71).

Cytotoxic T lymphocyte associated-4 (CTLA-4) gene. CTLA-4 or CD152 gene is a strong candidate for involvement in autoimmune diseases because it plays an important role in the termination of T cell activation (72). CTLA-4 gene is located on chromosome $2 \mathrm{q} 33$ region and studies carried out in different 
ethnic groups have demonstrated several SNPs on this gene that have been associated with susceptibility to MS. Some of these SNP are on exon $1(+49 \mathrm{~A} \rightarrow \mathrm{G})$, on a microsatellite marker at position 642 of exon 4 , and on the promoter regions $-318 \mathrm{C} \rightarrow \mathrm{T}$ and $-651 \mathrm{C} \rightarrow \mathrm{T}$ of the CTLA -4 gene (73). Interactions between CTLA-4 and HLA-DR2 genes in the development of MS were also reported $(74,75)$. The SNPs on position $+49 A \rightarrow G$, analyzed and on promoter regions $-318 \mathrm{C} \rightarrow \mathrm{T}$ and $-651 \mathrm{C} \rightarrow \mathrm{T}$ were analyzed in $133 \mathrm{MS}$ patients from the Japanese population and a statistical difference in the distribution of these SNPs between patients and control groups was not observed; however, the study suggested that the polymorphism may modulate the disease. Besides, an association between the CTLA-4 polymorphisms and variables such as age, disease prognostic and HLA-DRB1*1501 genotype was not observed. This study could not confirm that CTLA-4 gene polymorphisms are associated with susceptibility and clinical characteristics of MS (73).

Apolipoprotein E gene (ApoE). The protein apolipoprotein E (ApoE) has been the subject of considerable interest in MS (27) participating in repair processes within the CNS. A different clinical course of MS was associated with the presence of specific alleles. The neuroprotective effect of ApoE is allele-specific (with $\varepsilon 2>\varepsilon 3>\varepsilon 4$ allele) (76). Functional polymorphism of the ApoE gene would then be expected to affect the long-term outcome. The presence of the ApoE* ${ }^{*} 4$ allele or rather of the $\varepsilon 3 / \varepsilon 4$ genotype (the $\varepsilon 4 / \varepsilon 4$ genotype is rare) has been suggested as an unfavorable prognostic factor independent of age of onset, gender and duration of disease in different studies (77-83). However, other studies have not confirmed these findings (84-86). In most studies, individuals that carried the $\varepsilon 4$ allele seemed to show faster progression of the disease, while others reported that there are neither changes in the distribution of ApoE alleles in patients with MS nor correlation between ApoE genotypes and disease severity (87). The contradictory results may be explained, in part, by the fact that ApoE may influence disease severity by modifying disease course, such as association with conversion to secondary progressive disease course, which may not reflect the overall accumulating disability when a small number of individuals is studied and PP-MS patients are also included. Data have shown that carriers of the $\varepsilon 4$ allele of the ApoE gene had a significantly higher MRI lesion load than non-carriers (81). Although there was a trend for $\varepsilon 4$ carriers to have worse clinical disease, the difference compared with non-carriers was not significant until the sample size was increased (from 83 to 374 individuals) (83). The association between the ApoE and MS progression measured by clinical disability and MRI parameters was evaluated in a population-based patient sample $(n=70)$. Carriers of the ApoE- $\varepsilon 4$ alleles did not show a more severe disease progression, neither by EDSS/years of duration nor by the total lesion area/years duration (66). Although the study was carried out on a genetically homogeneous Danish population, the limited number of MS patients enrolled could interfere with the results obtained and the association between this gene and disease variables could not be excluded.

A study carried out in Italy evaluating the -491 ApoE polymorphism ( $\mathrm{A} \rightarrow \mathrm{T}$ substitution) in 236 individuals diagnosed with MS for at least three years showed no significant difference in the genotypic distribution $(\mathrm{P}=0.36)$ between $\mathrm{MS}$ and control group. Furthermore, no association was found between the ApoE- $\varepsilon 4$ allele and the progression of the disease. The study showed a slight association between the ApoE- 22 allele and a longer disease duration; patients with the $\varepsilon 3 / \varepsilon 2$ the genotype showed longer disease duration when compared with patients with the genotype $\varepsilon 3 / \varepsilon 3$ ( $13.5 \pm 7.6$ vs. $10.8 \pm 7.1$ years, respectively) or $\varepsilon 3 / \varepsilon 4(10.3 \pm 5.8$ years) $(87)$.

Genes associated with apoptosis. The Fas molecule, also named apolipoprotein-1 (Apo-1) or CD95, is a transmembrane glycoprotein apoptosis-signaling cell surface receptor belonging to the TNF receptor family. The Fas molecule is expressed on the surface of many types of cells, including lymphocytes, epithelial cells, fibroblasts and certain endothelial cells. Both Fas and FasL are expressed in activated mature $\mathrm{T}$ cells, and prolonged cell activation induces susceptibility to Fas-mediated apoptosis.

The Apo-1/Fas gene is located on chromosomal region 10q24.1 that shows linkage in MS genome screens, and studies indicate that there is an aberrant expression of Apo-1/Fas molecule in MS. The Mval polymorphism on the Apo-1/Fas promoter gene, which consists of an $A \rightarrow G$ substitution, was determined by PCR-RFLP from the DNA of 114 Japanese MS patients and of 121 healthy individuals. There was no statistical difference in the genotype and allelic frequencies among MS patients and controls showing no evidence that this polymorphism contributes to susceptibility to MS or that it is associated with the clinical course of the disease. Patients with the A/A genotype seem to have a later onset than those with $\mathrm{G} / \mathrm{G}$ or $\mathrm{G} / \mathrm{A}$ genotypes but this difference was not significant (88).

The TRAIL or Apo-2 ligand is a newly identified member of the TNF/nerve growth factor superfamily which has been mapped on human chromosome 3q26 (20) and is involved in cell death and some immunoregulatory mechanisms. The TRAIL gene is approximately $20 \mathrm{~kb}$ and is composed of five exons (89). Due to its implication in brain damage and the elevated expression in peripheral immune cells of MS patients, TRAIL may play a central role in the pathology of this disease. A highly polymorphic region in the TRAIL promoter with four SNPs within 11 base pairs was identified using single-strand conformation polymorphism analysis (90). The polymorphisms are located at positions $-707(\mathrm{C} \rightarrow \mathrm{T}),-665$ $(\mathrm{T} \rightarrow \mathrm{C}),-621(\mathrm{C} \rightarrow \mathrm{T})$ and $-597(\mathrm{~A} \rightarrow \mathrm{G})$ of the wild-type sequence. The SNP at position -707 was found within an AP-1 binding site. The variant haplotype frequency in 125 healthy individuals was $0.4 \%(-707 \mathrm{C} \rightarrow \mathrm{T}), 17.6 \%(-597 \mathrm{~A} \rightarrow \mathrm{G}), 6.8 \%(-621 \mathrm{C} \rightarrow \mathrm{T})$, $4.0 \%(-665 \mathrm{~T} \rightarrow \mathrm{C})$ and $71.2 \%$ (wild-type). In $123 \mathrm{RR}-\mathrm{MS}$ patients, the frequency of the SNPs detected was $7.7 \%$ (-621 $\mathrm{C} \rightarrow \mathrm{T}), 4.1 \%(-665 \mathrm{~T} \rightarrow \mathrm{C}), 16.2 \%(-597 \mathrm{~A} \rightarrow \mathrm{G})$ and $72.0 \%$ (wildtype). The -707 SNP was not detected in RR-MS patients. When 15 PP-MS patients were genotyped, the frequency observed of these SNPs was 3.3\% (-665 $\mathrm{T} \rightarrow \mathrm{C}), 20.0 \%(-597 \mathrm{~A} \rightarrow \mathrm{G})$ and $76.6 \%$ (wild-type). The SNPs -707 and -621 were not observed in PP-MS patients. No significant differences in the distribution of the genotypes were observed as to mean age at onset of the disease, disease progression (EDSS increase per year), and gender ratio. The authors suggested that these SNPs in the TRAIL promoter exert no impact on molecule expression, and are neither directly related to the increased risk of developing 
MS nor associated with a clinical course of this heterogeneous disease in German MS patients (90).

MHC classes I and II genes. The most important genetic factor of confirmed importance in MS has been identified in the HLA class II region. Evidence suggests that MS patients differ from control subjects in their MHC. Initially association was observed between MS and MHC class I $(91,92)$ and later with MHC class II regions (93). An association between MS and HLA-A3, B7, Dw2 haplotype in a North European population and a Caucasian population from the USA was observed (94); however, this association was not universal. Combination of HLA-DRB1*1501-DQA1*0102-DQB1*0602 (DR15) in northern Europeans $(86,92,95,96)$ and -DRB1*0301DQA1*0505-DQB1*0301 (DR3) in southern Europeans (97-99) was shown to increase the risk of MS 3-4 times. However, the data suggest that there may not be a single major susceptibility locus, and that genetic factors different than those related to the HLA region may also be involved $(27,93,100)$.

Susceptibility to MS was demonstrated, at first, with HLA-Dw2 and -DR2 specificities in Caucasian Europeans and North Americans. Further, with the use of genotype techniques, a positive association was demonstrated between MS and HLA-DRB1*1501, -DRB5*0101 and -DQA1*0602 genotypes in different ethnic groups worldwide (101-103). The relationship between HLA genotypes and disease severity (measured by brain MRI quantitative markers of demyelinating and destructive pathology in patients with MS) was evaluated in $100 \mathrm{MS}$ patients and 122 age-, gender-, ethnic- and residence-matched controls (104). HLA-DQB1*02 (OR, 19.9; 95\% CI, 16.2-24.3), -DQB1*03 (OR, 16.8; 95\% CI, 13.6-20.5), -DRB1*15 (OR, 4.6; 95\% CI, 3.7-5.6), and -DFRB1*03 (OR, $3.9 ; 95 \%$ CI, 3.2-4.8) alleles were associated with MS. When evaluated by intermediary determination methods, some HLA alleles may predict the destructive pathological processes visible on an MRI; however, the severity of disease was not significantly different according to the carrier status of these alleles. When the genotyping was evaluated by a high determination method, in a study carried out in Italian MS patients, the results demonstrated a strong association between the HLA-DRB1*1501, -DQB1*0301, -DQB1*0302, -DQB1*0602 and -DQB1*0603 alleles and severe neurodegenerative and inflammatory damages obtained by MRI (105).

A negative association with HLA-DR1, HLA-DQ5 and -DRB1*01 was demonstrated in North and West European, Canary Island and Italian populations $(98,106-108)$. HLA-DR2 was associated with susceptibility to MS in most of the Western hemisphere, while HLA-DR3 and -DR4 were associated with susceptibility to MS in Sardinia, Italy (109). Another study demonstrated that in the Sardinian population, MS was associated with HLA-DR4 (98) and, in individuals from Latin America (Mexico), was identified a relationship with HLA-DRw6 and the subtype DRw13 (110).

A significantly higher frequency of HLA-DRB1*1501 was observed in 133 Japanese MS patients (OR, 2.29; 95\% CI, 1.32-3.98) than in healthy controls (73). An association between HLA-DRB1*1501, -DQA1*0102, -DQB1*0602 haplotypes with clinical form, disease duration and disability, evaluated with EDSS, was observed in Iranian MS patients (111). However, the authors discussed that patient enrollment from different parts of the country with varied ethnicities may be a limiting factor for the results.

T-cell receptor (TCR) gene. The HLA-DRB1* and TCR polymorphisms were evaluated in 358 clinically well-characterized MS patients from Germany, grouped according to the course of MS, and in 395 healthy subjects. The relative risk for MS in HLA-DRB1 ${ }^{*} 15^{+}$and -DRB1*03+ individuals were 3.6 and 1.4, respectively. In MS patients, certain TCRB gene polymorphisms were risk factors. In HLA-DRB1 ${ }^{*} 03^{+}$individuals, the relative risk was increased (>22.0) when a specific TCRBV6S3 allele was also inherited. Furthermore, distinct linkage disequilibria of TCRBV6S3 elements in patients and control subjects strongly suggest an additional risk factor in the TCRBV region for -DRB1* $15^{+}$individuals (112).

\section{Genetic polymorphism and MS in the Brazilian population}

Brazilians represent one of the most genetically heterogeneous population in the world, the result of five centuries of interethnic crosses between people from three continents including the European colonizers, represented mainly by Portuguese; African slaves (mainly from West-Central Africa); and the native Amerindians $(113,114)$. The present Brazilian population includes Europeans from southern Europe (Portuguese and Italian) and Middle Easterners, Asians, Arabians, Africans and native Amerindians (115-117). This extensive ethnic miscegenation has suggested that other alleles may be involved in the autoimmune response and pathogenesis of MS and thus, influences the susceptibility and resistance to MS.

Cytokines and their receptor genes. Studies using tissue lesions obtained from MS patients showed an association between numerous cytokines with CNS inflammation. A change from the $\mathrm{CD} 4^{+} \mathrm{Th} 1$ phenotype to the $\mathrm{CD} 4^{+} \mathrm{Th} 2$ pattern response, which is observed during remission of the disease, may result in a decreased immune response with anti-inflammatory or regulatory cytokine production, such as IL-4 and IL-10. The IL-4 gene has mono and biallelic expression and is located on 5q31-33 chromosome that codes cytokines from the Th2 pattern response. Polymorphism in the cytokine regulatory genes can influence the amount of cytokine produced. A SNP at the IL-4 gene, region +33 that results in a substitution of $\mathrm{C} \rightarrow \mathrm{T}$, increases this cytokine production. The clinical symptoms that are found in MS can be correlated with the expression of IL-4 and the IL-4R. A research carried out in Rio de Janeiro, Brazil, with 129 MS patients and 135 healthy individuals, showed no significant differences in the genotypic and allelic frequency of the IL-4 promoter gene polymorphism and for the Q551R polymorphism in the IL-4R gene. Nevertheless, the SNP +33 genotyping showed a slight decrease in the TT genotype (4.6\% in MS patients vs. $6.7 \%$ in control subjects) and a slight increase in the CT genotype in MS patients $(41.1 \%$ in MS patients vs. 37.4\% in control subjects). Likewise, MS patients showed a higher percentage (12.5\%) of the CC allele of the Q551R polymorphism on the IL-4R gene than controls (8.1\%). When ethnicity was considered, Black MS patients had seven times higher chance to carry the TT allele of the IL-4 gene when compared to Caucasian patients (9.1 vs. 1.3\%). 
In the control group, differences were not found. Similarly, Black MS patients showed a 3-fold greater chance to carry the $\mathrm{CC}$ allele of the IL-4R gene when compared to Caucasian patients (20.0 vs. $6.8 \%$ ); also no difference was found in the controls. These results suggest that IL-4 and IL-4R genotypes may influence the state of MS in the Brazilian population. The increased percentage of the TT allele of the IL-4 gene and the CC allele of IL-4R gene in subjects African descent suggest an adaptation of African descendants to different antigenic and pathogenic challenges that influence cytokine equilibrium of the Th1 and Th2 responses. The data showed that both IL-4 and IL-4R genes are susceptibility factors to MS and may be able to modify the disease risk depending on the ethnicity and penetrance of susceptibility factors (118).

Chemokines and their receptor genes. The frequency of the CCR5- $\Delta 32$ allele was assessed in unrelated healthy individuals from different regions of Brazil. The frequencies of CCR5 homozygous (wild-type) and CCR5- $\Delta 32$ heterozygous individuals were 93.0 and $7.0 \%$, respectively. No homozygous genotype for the CCR5- $\Delta 32$ allele was detected, resulting in an allelic frequency of 0.035 (119). The prevalence of CCR5- $\Delta 32$ was investigated in a random sample of healthy individuals from Alegrete, in southern Brazil, where the population was basically established from a mixture of Spanish, Portuguese and African individuals and native Amerindians. No CCR5- $\Delta 32$ homozygous genotype was detected and the presence of the CCR5 wild-type genotype among whites, blacks and mulattos was $14.0,8.0$ and $13.0 \%$, respectively, indicating a CCR5- $\triangle 32$ allele frequency of $0.068,0.038$ and 0.064 , respectively (113).

The association between the CCR5- $\Delta 32$ allele with the clinical course and MRI was analyzed in 124 unrelated MS outpatients (evaluated by the EDSS for the disease severity), and in 127 unrelated healthy blood donors from a similar geographical area, located in Londrina, southern Brazil (15). The frequency of the CCR5 wild-type and CCR5- $\triangle 32$ heterozygous genotypes was 90.4 and $9.6 \%$, respectively, in MS patients. No homozygosity for the CCR5- $\Delta 32$ was found, resulting in an overall CCR5- $\Delta 32$ frequency of 0.0484 among the patients. The frequencies among healthy individuals was 90.5\% for the CCR5 wild-type, $7.9 \%$ for the CCR5- $\Delta 32$ heterozygous and $1.6 \%$ form the CCR5- $\Delta 32$ homozygous genotypes, resulting in an overall frequency of CCR $5-\Delta 32$ of 0.0055 among healthy controls. No significant difference was observed in the distribution of genotypes between MS patients and healthy subjects. An association between the CCR5 gene polymorphism and the clinical course of MS was also not found. Despite the fact that the differences were not significant, the results suggest that the disease onset and progression to disability may be prolonged in MS carriers of the CCR5- $\Delta 32$ allele, when compared with individuals with fully functional CCR5, by 11.2 and 7.7 years respectively. MRIs identified lower positive gadolinium enhancing-imaging at brain lesions and lower brain atrophy $\mathrm{n} \mathrm{MS} \mathrm{patients} \mathrm{with} \mathrm{the} \mathrm{CCR5-} \triangle 32$ allele than in those with the wild-type genotype. Taken together, the results suggest that CCR $5-\Delta 32$ could be considered a favorable prognostic biomarker of MS in this population.

MHC class II genes. The evaluation of the HLA-DRB gene in a Brazilian population has a particular interest in showing the behavior of the HLA-DRB1 allele in a heterogeneous population placed in an environment of low prevalence of MS. Studies carried out in Brazilian patients with an African descent, showed a association between MS and HLA-DQB1*0602, in agreement to others studies, even without the presence of the -DRB1*1501 allele (120). A positive association between the MS and -DQB1 ${ }^{*} 0602$, and -DQA1*0102 alleles was also found (121). The low frequency of the -DPA1*0301 allele observed indicated a protective role for MS. However, another study showed that the immune response seems not to be solely influenced by the expression of HLA-QB1*060 allele, because statistical significance was not observed between this allele and MS patients and control groups (122). As demonstrated from other researchers the HLA-DQA1*0201-0301 alleles were associated with the white Brazilian population; the -DRB1*1501 allele was present in white Brazilians and confers an ethnicity-dependent MS susceptibility in white MS patients; the -DQB1*0602 allele confers genetic susceptibility regardless of ethnicity (123). An association between the HLA-DRB1*1501 and -DRB1*1503 alleles and MS white and mulatto individuals from the Brazilian population was also observed (124).

The association between the HLA-DRB1*15 allele and MS was evaluated in a Brazilian Caucasian population sample from Londrina, southern Brazil (125). HLA-DRB1 alleles were analyzed by PCR with specific sequence oligonucleotide primers (PCR-SSOP) in 119 MS patients and in 305 healthy blood donors as controls. The HLA-DRB1*15 allele was identified as a significant susceptibility factor for MS development (OR, 2.53; 95\% CI, 1.43-4.46) and the HLA-DRB1*11 allele with a trend significant to be a susceptibility factor for MS development (OR, 0.67; 95\% CI, 0.44-1.03). It was observed that, for the -DRB1*11 allele, homozygocity may confer resistance in disease development. The homozygous for the -DRB1*15 allele did not present any effect in MS susceptibility, probably because of the limited number of homozygous patients for this allele evaluated in the study. In a study comparing the heterozygous pairs between controls and MS patients, represented by $-\mathrm{DRB} 1^{*} 15 / \mathrm{X}$, where $\mathrm{X}$ represents others alleles in combination with the 15 allele, a significant difference in the occurrence of heterozygous pairs -DRB1*15/03 and -DRB1*15/14, was verified, suggesting that this heterozygocity is associated with increased susceptibility to MS.

A study carried out among patients from Lagoa Hospital, Rio de Janeiro, identified a role for the HLA-DR2 haplotypes (HLA-DRB1*1501 and -DQB1*0602) in PP-MS patients. The disease was more severe in patients with the -DRB1*1501 haplotype, underscoring the importance of this genetic factor in the heterogeneity and clinical course of MS (126).

\section{Final considerations}

MS is a complex disease and its development and clinical course are not only related to individual genetic predisposition, but also dependent on a number of other factors, such as environmental, geographical and individual immune responses against certain infectious agents. The detection of a SNP involved in the etiology and physiopathology is very difficult and probably, several genetic polymorphisms are involved, each with a small contribution to the susceptibility or resistance to MS. 
Considerable attention has been devoted to studies evaluating disease modifying effects in MS. Seven genes of probable importance have thus been identified: HLA class II, ApoE, IL-1RA, IL-1 $\beta$, TNF- $\alpha$, TNF- $\beta$ (or LTa) and CCR5. The variant alleles may contribute to the heterogeneity in disease course by different mechanisms (27). However, the results described in the literature about genetic biomarkers of MS are not consistent in the worldwide population. All of the data reviewed in the present study have been obtained in population association studies. Although this design is the easiest to conduct, the results are confounded by ethnic differences. Family-based association methods matching for ethnicity and sufficient confirmation in other data sets can circumvent this problem. All the results together show the need for continued research in the genetically heterogeneous populations. Collaborations between investigators are essential to identify new biomarkers associated with MS that could be used as therapeutic targets to modulate the autoimmune response in MS patients. This information may contribute to a better understanding of the physiopathology and treatment of MS, with the possibility of developing different therapeutic strategies according to the genetic profile of each individual.

\section{References}

1. Miller JR: Esclerose múltipla. In: Tratado de Neurologia. 10th edition. Rowland LP and Merrit MD (eds). Guanabara Koogan, Rio de Janeiro, pp670-686, 2002.

2. Adams AD and Victor M: Neurologia. 6th edition. McGraw Hill, Rio de Janeiro, 1998.

3. Seboun E, Oksenberg JR and Hauser SL: Molecular and genetic aspects of multiple sclerosis. In: The Molecular and Genetic Basis of Neurological Disease. 2nd edition. Rosenberg RN, Prusiner SB, DiMauro S and Barchi RL (eds). ButterworthHeinemann, Boston, pp631-660, 1997.

4. Poser CM: Multiple sclerosis, observations and reflections-a personal memoir. J Neurol Sci 107: 127-140, 1991.

5. McDonald WI, Compston A, Edan G, et al: Recommended diagnostic criteria for multiple sclerosis: guidelines from the International Panel on the diagnosis of multiple sclerosis. Ann Neurol 50: 121-127, 2001.

6. Lublin FD and Reingold SC: Defining the clinical course of MS. Neurology 45: 907-911, 1996.

7. World Health Organization: Neurological Disorders: Public Health Challenges, WHO Press, Geneva, 2006.

8. Runmarker B and Andersen O: Prognostic factors in a multiple sclerosis incidence cohort with 25 years of follow-up. Brain 116 117-134, 1993

9. McFarland FH: Correlation between MR and clinical findings of disease activity in multiple sclerosis. AJNR Am J Neuroradiol 20: 1777-1778, 1999.

10. Raine CS and Scheinberg LC: On the immunopathology of plaque development and repair in multiple sclerosis. J Neuroimmunol 20: 189-201, 1988.

11. Lucchinetti C, Bruck W, Parisi J, Scheithauer B, Rodriguez M and Lassamann H: Heterogeneity of multiple sclerosis lesions: implications for the pathogenesis of demyelination. Ann Neurol 47: 707-717, 2000.

12. Polman $\mathrm{CH}$, Reingold SC, Edan G, et al: Diagnostic criteria for multiple sclerosis: 2005 revisions to the 'McDonald Criteria' Ann Neurol 58: 840-846, 2005.

13. Gonzalez-Scarano F, Grossman RI, Galetta S, Atlas SW and Silberberg DH: Multiple sclerosis disease activity correlates with gadolinium-enhanced magnetic resonance imaging. Ann Neurol 21: 300-306, 1987

14. Sospedra M and Martin M: Immunology of multiple sclerosis. Ann Rev Immunol 23: 683-747, 2005.

15. Kaimen-Maciel DR, Reiche EM,Brum-Souza DG, et al: CCR5 432 genetic polymorphism associated with benign clinical course and magnetic resonance imaging findings in Brazilian patients with multiple sclerosis. Int J Mol Med 20: 337-344, 2007.
16. Girolami U, Anthony DC and Frosch MP: O sistema nervoso central. In: Robbins Patologia Estrutural e Funcional. 6th edition. Cotran RS, Kumar V and Collins T (eds). Guanabara Koogan, Rio de Janeiro, pp1198-1202, 2000.

17. McDonald WI and Ron MA: Multiple sclerosis: the disease and its manifestations. Philos Trans R Soc Lond B Biol Sci 354: 1615-1622, 1999.

18. Kantarci $\mathrm{OH}$, Morales Y,ZiemerPA, et al: CCR5 $\Delta 32$ polymorphism effects on CCR5 expression, patterns of immunopathology and disease course in multiple sclerosis. J Neuroimmunol 169: 137-143, 2005.

19. Gold R, Hartung HP and Lassmann H: T-cell apoptosis in autoimmune diseases: termination of inflammation in the nervous system and other sites with specialized immune-defense mechanisms. Trends Neurosci 20: 399-404, 1997.

20. Wiley SR, Schooley K, Smolak PJ, et al: Identification and characterization of a new member of the TNF family that induces apoptosis. Immunity 3: 673-682, 1995.

21. Nitsch R, Bechmann I, Deisz RA, et al: Human brain-cell death induced by tumour-necrosis-factor-related apoptosis-inducing ligand (TRAIL). Lancet 356: 827-828, 2000.

22. Aktas O, Osmanova V, Beyer M, Brocke S and Zipp F: Therapeutic modulation of the TRAIL system in autoimmune CNS inflammation. J Neuroimmunol 118: 52, 2001.

23. Mycko M, Kowalski W, Kwinkovski M, et al: Multiple sclerosis: the frequency of allelic forms of tumor necrosis factor or lymphotoxin-alpha. J Neuroimmunol 84: 198-206, 1998.

24. Bugeja MJ, Booth D, Bennett B, Heard R, Rubio J and Stewart G: An investigation of polymorphisms in the 17q11.2-12 CC chemokine gene cluster for association with multiple sclerosis in Australians. BMC Med Genet 7: 64, 2006.

25. Simpson J, Rezaie P, Newcombe J, Cuzner ML, Male D and Woodroofe MN: Expression of the $\beta$-chemokine CCR2, CCR3 and CCR5 in multiple sclerosis central nervous system tissue. J Neuroimmunol 108: 192-200, 2000

26. Szczucinski A and Losy J: Chemokines and chemokines receptors in multiple sclerosis. Potential targets for new therapies. Acta Neurol Scan 115: 137-146, 2007.

27. Kantarci $\mathrm{OH}$, Andrade $\mathrm{M}$ and Weinshenker BG: Identifying disease modifying genes in multiple sclerosis. J Neuroimmunol 123: 144-159, 2002 .

28. Martinez Doncel A, Rubio A, Arroyo R, et al: Interleukin-10 polymorphisms in Spanish multiple sclerosis patients. J Neuroimmunol 131: 168-172, 2002.

29. Nakajima H, Fukuda K, Doi Y, et al: Expression of Th1/Th2-related chemokine receptors on peripheral $\mathrm{T}$ cells and correlation with clinical disease activity in patients with multiple sclerosis. Eur J Neurol 52: 162-168, 2004.

30. Calderon TM, Eugenin EA, Lopez L, et al: A role for CXCL12 (SDF-1alpha) in the pathogenesis of multiple sclerosis: regulation of CXCL12 expression in astrocytes by soluble myelin basic protein. J Neuroimmunol 111: 27-39, 2006.

31. Smith KJ and McDonald WI: The pathophysiology of multiple sclerosis: the mechanisms underlying the production of symptoms and the natural history of the disease. Philos Trans R Soc Lond B Biol Sci 354: 1649-1673, 1999.

32. Achiron A: Chemokine polymorphisms: candidates for MS susceptibility and disease course. Int MS J 11: 71-77, 2004.

33. Kantarci $\mathrm{OH}$, Atkinson EJ, Hebrink DD, Mcmurray $\mathrm{C}$ and Weinshenker BG: Association of two variants in IL-1 $\beta$ and IL-1 receptor antagonist genes with multiple sclerosis. J Neuroimmunol 106: 220-227, 2000.

34. Schrijver HM, Crusius JB, Uitdehaag BM, et al: Association of interleukin 1 beta and inteleukin-1 receptor antagonist genes with disease severity in MS. Neurology 52: 595-599, 1999.

35. Mann CLA, Davies MB, Boggild M, et al: Polymorphisms at the IL-1RN and IL-1beta loci influence disability in multiple sclerosis. Mult Scler 4: 34, 1998.

36. Feakes R, Sawcer S, Broadley S, et al: Interleukin 1 receptor antagonist (IL-1ra) in multiple sclerosis. J Neuroimmunol 105: 96-101, 2000

37. Pickard C, Mann C, Sinnott P, et al: Interleukin-10 (IL10) promoter polymorphisms and multiple sclerosis. J Neuroimmunol 101: 207-210, 1999.

38. Mäurer M, Kruse N, Giess R, Toyka KV and Rieckmann P: Genetic variation at position -1082 of the interleukin 10 (IL10) promotor and the outcome of multiple sclerosis. J Neuroimmunol 104: 98-100, 2000.

39. Martinez-Caceres EM, Espejo C, Brieva L, et al: Expression of chemokine receptors in the different clinical forms of multiple sclerosis. Mult Scler 8: 390-395, 2002. 
40. Luomala M, Lehtimaki T, Huhtala H, et al: Promoter polymorphism of IL-10 and severity of multiple sclerosis. Acta Neurol Scand 108: 396-400, 2003.

41. Wergeland S, Beiske A, Nyland H, et al: IL-10 promoter haplotype influence on interferon treatment response in multiple sclerosis. Eur Neurol 2: 171-175, 2005.

42. Cavanillas ML, Alcina A, Núñez C, et al: Polymorphisms in the IL2, IL2RA and IL2RB genes in multiple sclerosis risk. Eur J Hum Genet 18: 794-799, 2010.

43. Kirk CW, Droogan AG, Hawkins SA, McMillan SA, Nevin NC, and Grahamn CA: Tumour necrosis factor microsatellites show association with multiple sclerosis. J Neurol Sci 147: 21-25, 1997.

44. McDonnell GV, Kirk CW, Middleton D, et al: Genetic association studies of tumor necrosis factor $\alpha$ and $\beta$ and tumor necrosis factor receptor 1 and 2 polymorphisms across the clinical spectrum of multiple sclerosis. J Neurol 246: 1051-1058, 1999.

45. Bruce AJ, Boling W, Kindy MS, et al: Altered neuronal and microglial responses to excitotoxic and ischemic brain injury in mice lacking TNF receptors. Nat Med 2: 788-794, 1996.

46. Huizinga TW, Westendorp RG, Bollen EL, et al: TNF- $\alpha$ promoter polymorphisms, production and susceptibility to multiple sclerosis in different group of patients. J Neuroimmunol 72: 149-153, 1997.

47. Mäurer M, Kruse N, Giess R, Kyriallis K, Toyka KV and Rieckmann P: Gene polymorphism at position -308 of the tumor necrosis factor $\alpha$ promoter is not associated with disease progression in multiple sclerosis patients. J Neurol 246: 949-954, 1999.

48. He B, Navikas V, Lundahl J, Söderström M and Hillert J: Tumor necrosis factor $\alpha-308$ alleles in multiple sclerosis and optic neuritis. J Neuroimmunol 63: 143-147, 1995.

49. Lucotte G, Bathelier C and Mercier G: TNF-alpha polymorphisms in multiple sclerosis: no association with -238 and -308 promoter alleles, but the microsatellite allele a11 is associated with the disease in French patients. Mult Scler 6: 78-80, 2000.

50. Messer G, Spengler U, Jung MC, et al: Polymorphic structure of the tumor necrosis factor (TNF) locus: an Ncol polymorphism in the first intron of the human TNF-beta gene correlates with a variant amino acid in position 26 and a reduced level of TNF-beta production. J Exp Med 173: 209-219, 1991.

51. Fernandez-Arquero M, Arroyo R, Rubio A, et al: Primary association of a TNF gene polymorphism with susceptibility to multiple sclerosis. Neurology 53: 1361-1363, 1999.

52. Drulovic J, Popadic D, Mesaros S, et al: Decreased frequency of the tumor necrosis factor alpha -308 allele in Serbian patients with multiple sclerosis. Eur Neurol 50: 25-29, 2003.

53. Martinez A, Rubio A, Urcelay E, et al: TNF-376A marks susceptibility to MS in the Spanish population: a replication study. Neurology 62: 809-810, 2004.

54. Weinshenker BG, Hebrink D, Wingerchuck DM, et al: Genetic variants in the tumor necrosis factor receptor 1 gene in patients with MS. Neurology 52: 1500-1503, 1999.

55. Pras E, Aksentijevich I, Shinar Y, Kastner DL and Achiron A: Lack of evidence for an association between two genetic polymorphisms in the tumor necrosis factor receptor 1 gene and multiple sclerosis in Ashkenazi Jews. Eur Neurol 46: 153-155, 2001.

56. Ehling R, Gassner C, Lutterotti A, et al: Genetics variants in the tumor necroses factor receptor II gene in patients with multiple sclerosis. Tissue Antigens 63: 28-33, 2003.

57. Liu R, Paxton WA, Choe S, et al: Homozygous defect in HIV-1 coreceptor accounts for resistance of some multiply-exposed individuals to HIV-1 infection. Cell 86: 367-377, 1996.

58. Simpson JE, Newcombe J, Cuzner ML and Woodroofe MN: Expression of monocyte chemoattractant protein-1 and other $\beta$-chemokines by resident glia and inflammatory cells in multiple sclerosis lesions. J Neuroimmunol 84: 238-244, 1998.

59. Dean M, Carrington M, Winkler C, et al: Genetic restriction of HIV-1 infection and progression to AIDS by a deletion allele of the CKR5 structural gene. Science 273: 1856-1862, 1996.

60. Samsom M, Libert F, Doranz BJ, et al: Resistance to HIV-1 infection in Caucasian individuals bearing mutant alleles of the CCR-5 chemokine receptor gene. Nature 382: 722-724, 1996.

61. Martinson JJ, Chapman NH, Rees DC, Liu YT and Clegg JB: Global distribution of the CCR5 gene 32-basepair deletion. Nat Genet 16: 100-103, 1997.

62. Voevodin A, Samilchuk E and Dashti S: A survey for 32 nucleotide deletion in the CCR-5 chemokine receptor gene (delta ccr-5) conferring resistance to human immunodeficiency virus type 1 in different ethnic groups and in chimpanzees. J Med Virol 55: 147-151, 1988
63. Libert F, Cochaux P, Beckman G, et al: The deltaccr5 mutation conferring protection against HIV-1 in Caucasian populations has a single and recent origin in Northeastern Europe. Hum Mol Genet 7: 399-406, 1998

64. Sellebjerg F, Madsen HO, Jensen CV, Jenses J and Garred P: CCR5- $\Delta 32$, matrix metalloproteinase- 9 and disease activity in multiple sclerosis. J Neuroimmunol 102: 98-106, 2000.

65. Barcellos LF, Schito AM and Rimmler JB: CC-chemokine receptor 5 polymorphism and age of onset in familial multiple sclerosis. Multiple Sclerosis Genetics Group. Immunogenetics 51: 281-288, 2000

66. Schreiber K, Otura AB, Ryder LP, et al: Disease severity in Danish multiple sclerosis patients evaluated by MRI and three genetic markers (HLA-DRB1*1501, CCR5 deletion mutation, apolipoprotein E). Mult Scler 8: 295-298, 2002.

67. Kantor R, Bakhanashvili M and Achorin A: A mutated CCR5 gene may have favorable prognostic implications in MS. Neurology 61: 238-240, 2003.

68. Bennets BH, Teutsch SM, Buhler MM, Hjeard RN and Stewart GJ: The CCR5 deletion mutation fails to protect against multiple sclerosis. Hum Immunol 58: 52-59, 1997.

69. Gade-Andavolu R, Comings DE, Macmurray J, et al: Association of CCR5 delta 32 deletion with early death in multiple sclerosis. Genet Med 6: 126-131, 2004.

70. Silversides JA, Heggarty SV, Mcdonnell GV, Hawkins SA and Graham CA: Influence of CCR5 delta 32 polymorphism on multiple sclerosis susceptibility and disease course. Mult Scler 10: 149-152, 2004.

71. Ristic S, Lovrecic L, Starcevic-Cizmarevic A, et al: No association of CCR5- $\triangle 32$ gene mutation with multiple sclerosis in Croatian and Slovenian patients. Mult Scler 12: 360-362, 2006.

72. Waterhouse P, Penninger JM, Timms E, et al: Lymphoproliferative disorders with early lethality in mice deficient in Ctla-4. Science 270: 985-988, 1995.

73. Fukazawa T, Kikuchi S, Miyagishi R, et al: CTLA-4 gene polymorphism is not associated with conventional multiple sclerosis in Japanese. J Neuroimmunol 159: 225-229, 2005.

74. Rasmussen HB, Kelly MA, Francis DA and Lausen J: CTLA-4 in multiple sclerosis. Lack of genetic association in a European population but evidence of interaction with HLA-DR2 among Shanghai Chinese. J Neuroimmunol 184: 143-147, 2001.

75. Alizadehet HM, Babron MC, Birebent B, et al: Genetic interaction of CTLA-4 with HLA-DR15 in multiple sclerosis. Ann Neurol 54: 119-122, 2003.

76. Miyata M and Smith JD: Apolipoprotein E allele-specific antioxidant activity and effects on cytotoxicity by oxidative insults and beta-amyloid peptides. Nat Genet 14: 55-61, 1996.

77. Dousset V, Gayou A, Brochet B and Iron A: ApoE polymorphism in multiple sclerosis. Mult Scler 4: 357, 1998.

78. Evangelou N, Jackson M, Beeson D and Palace J: Association of the ApoE $\varepsilon 4$ allele with disease activity in multiple sclerosis. J Neurol Neurosurg Psychiatry 67: 203-205, 1999.

79. Hogh P, Oturai A, Screiber K and Blinkerberg M: Apolipoprotein $\mathrm{E}$ and multiple sclerosis: impact of the epsilon- 4 allele on susceptibility, clinical and progression rate. Mult Scler 6: 226-230, 2000.

80. Masterman T, Hillert J, Lannfelt L and Corder EH: The $\varepsilon 4$ allele for ApoE doubles the risk of long-term prognosis in multiple sclerosis. Am J Hum Genet 67: 1957, 2000.

81. Fazekas F, Strasser-Fuchs S, Schmidt H, et al: Apolipoprotein E genotype related differences in brain lesions of multiple sclerosis. J Neurol Neurosurg Pscychiatry 69: 25-28, 2000.

82. Chapman J, Vinokurov S, Achiron A, et al: ApoE genotype is a major predictor of long-term progression of disability in MS. Neurololy 56: 312-316, 2001.

83. Fazekas F, Strasser-Fuchs S, Kollegger H, et al: Apolipoprotein E epsilon4 is associated with rapid progression of multiple sclerosis. Neurology 57: 853-857, 2001.

84. Ferri C, Sciacca FL, Veglia F, et al: ApoE epsilon2-4 and -491 polymorphism are not associated with MS. Neurology 53: 888-889, 1999.

85. Weatherby SJ, Mann CL, Davies MB, et al: Polymorphisms of apolipoprotein E: outcome and susceptibility in multiple sclerosis. Mult Scler 6: 32-36, 2000.

86. Haines JL, Schmidt S, Boylston FR, et al: Follow-up analysis of the chromosome 19q13 region in multiple sclerosis with singlenucleotide polymorphisms. Neurology 56 (Suppl 3): A96, 2001.

87. Savettieri G, Andreoli V, Bonavita S, et al: Apolipoprotein E genotype does not influence the progression of multiple sclerosis. J Neurol 250: 1094-1098, 2003. 
88. Niino M, Kikuchi S, Fukazawa T, Miyagishi R, Yabe I and Tashiro K: Na examination of the Apo-I/Fas Mva I polymorphism in Japanese patients with multiple sclerosis. BMC Neurol 2: 8, 2002.

89. Gong B and Almasan A: Genomic organization and transcriptional regulation of human Apo2/TRAIL gene. Biochem Biophys Res Commun 278: 747-752, 2000.

90. Weber A, Wandinger KP, Mueller W, et al: Identification and functional characterization of a highly polymorphic region in the TRAIL promoter in multiple sclerosis. J Neuroimmunol 149: 95-201, 2004.

91. Naito S, Namerow N, Mickey M and Terasaki PI: Multiple Sclerosis: association with HL-A3. Tissue Antigens 2: 1-4, 1972.

92. Jersild C, Svejgaard A and Fog T: HLA antigens and multiple sclerosis. Lancet 2: 240-241, 1972.

93. Winchester R, Ebers GC, Fu SM, Espinosa L, Zabriskie J and Kunkel HG: B-cell alloantigen Ag7a in multiple sclerosis. Lancet 2: 814, 1975 .

94. Brautbar C, Amar A, Cohen I, et al: Histocompatibility (HLA) antigens and multiple sclerosis in Israelis. Isr J Med Sci 18: 631-634, 1982

95. Compston DA: The genetic epidemiology of multiple sclerosis Philos Trans R Soc B Biol Sci 354: 1623-1634, 1999.

96. Soderstrom M, Ya-Ping J, Hillert J and Link H: Optic neuritis prognosis for multiple sclerosis from MRI, CSF, and HLA findings. Neurology 50: 708-714, 1998.

97. Saruhan-Dirreskenel G, Esin S, Baykan-Kurt B, et al: HLA-DR and DQ associations with multiple sclerosis in Turkey. Hum Immunol 55: 59-65, 1997.

98. Coraddu F, Reyes-Yañes MP, Parra A, et al: HLA associations with multiple sclerosis in the Canary Islands. J Neuroimmunol 87: 130-135, 1998.

99. Marrosu MG, Murru MR, Costa G, Murru R, Muntoni F and Cucca F: DRB1-DQA1-DQB1 loci and multiple sclerosis predisposition in the Sardinian population. Hum Mol Genet 7: 1235-1237, 1998

100. Compston DA, Batchelor JR and McDonald WI: B-lymphocyte alloantigens associated with multiple sclerosis. Lancet 2 $1261-1265,1976$.

101. Olerup O and Hillert J: HLA class II- associated genetic susceptibility in multiple sclerosis: a critical evaluation. Tissue Antigens 38: 1-15, 1991.

102. Fogdell A, Hillert J, Sachs C and Olerup O: The multiple sclerosisand narcolepsy-associated HLA class II haplotype includes the DRB5*0101 allele. Tissue Antigens 4: 333-336, 1995.

103. Dyment DA, Stecklev JL, Morrison K, Willer CJ, Cader MZ, DeLuca GC, Sadovnick AD, Risch N, Ebers GC; Canadian Collaborative Study Group. TCR beta polymorphisms and multiple sclerosis. Genes Immun 5: 337-342, 2004.

104.Zivadinov R, Uxa L, Zacchi T, et al: HLA genotypes and disease severity assessed by magnetic resonance imaging findings in patients with multiple sclerosis. J Neurol 250 1099-1106, 2003

105. Zivadinov R, Uxa L, Bratina A, et al: HLA-DRB1*1501, -DQB1*0301, -DQB1*0302, -DQB1*0602, and -DQB1*0603 alleles are associated with more severe disease outcome on MRI in patients with multiple sclerosis. Int Rev Neurobiol 79: 521-535, 2007.

106. Weinshenker BG, Santrach P, Bissonet AS, et al: Major histocompatibility complex class alleles and the course and outcome of MS: a population-based study. Neurology 5: 742-747, 1998.

107. Silva A, Kesselring J and Thompson A: Frontiers in Multiple Sclerosis. Vol. 2. 1st edition. Martin Dunitz Ltd., London, pp51-61, 1999.

108. Hillert J: Human leukocyte antigen studies in multiple sclerosis. Ann Neurol 36: 15-17, 1994
109. Marrosu MG, Murru MR, Costa G, et al: Multiple sclerosis in Sardinia is associated and in linkage disequilibrium with HLA-DR3 and -DR4 alleles. Am J Hum Genet 61: 454-457, 1997.

110. Gorodezky C, Najera R, Rangel BE, et al: Immunogenetic profile of multiple sclerosis in Mexicans. Hum Immunol 16 364-374, 1986

111. Ghabaee M, Bayati A, Amri Saroukolaei S, et al: Analysis of HLA DR2\&DQ6 (DRB1*1501, DQA1*0102, DQB1*0602) haplotypes in Iranian patients with multiple sclerosis. Cell Mol Neurobiol 20: 109-114, 2009

112. Epplen C, Jackel S, Santos EJ, et al: Genetic predisposition to multiple sclerosis as revealed by immunoprinting. Ann Neurol 41: 341-352, 1997.

113. Vargas AE, Marrero AR, Salzano FM, Bortolini MC and Chies JA: Frequency of CCR5- $\triangle 32$ in Brazilian populations. Braz J Med Biol Res 39: 321-325, 2006.

114. Alves-Silva J, Da Silva Santos M, Guimarães PE, et al: The ancestry of Brazilian mtDNA lineages. Am J Hum Genet 67: 444-461, 2000.

115. Mikawa AY, Tagliavini SA and Costa PI: CCR5 genotype and plasma $\beta$-chemokine concentration of Brazilian HIV-infected individuals. Braz J Med Biol Res 35: 1333-1337, 2002.

116. Parra FC, Amado RC, Lambertucci JR, Rocha J, Antunes CM and Pena SD: Color and genomic ancestry in Brazilians. Proc Natl Acad Sci USA 100: 177-182, 2003.

117. Pimenta JR, Zuccherato LW, Debes AA, et al: Color and genomic ancestry in Brazilians: a study with forensic microsatellites. Hum Hered 62: 190-195, 2006.

118. Quirico-Santos T, Suppiah V, Heggarty S, Caetano R, Alves-Leon S and Vandenbroeck K: Study of polymorphisms in the interleukin-4 and IL-4 receptor genes in a population of Brazilian patients with multiple sclerosis. Arq Neuropsiquiatr 65: 15-19, 2007.

119. Passos GA Jr and Picanco V: Frequency of the delta CCR5 deletion in the urban Brazilian population. Immunol Lett 61: 205-207, 1998

120. Caballero A, Alves-Leon S, Papais-Alvarenga R, Fernandez O, Navarro G and Alonso A: DQB1*0602 confers genetic susceptibility to multiple sclerosis in Afro-Brazilians. Tissue Antigens 54: 524-526, 1999.

121. Santos CC, Quirico-Santos T, Frugulhetti I and Alves-Leon SV: Analysis of HLA-DQ, DP, DR alleles associated with multiple sclerosis susceptibility in a population from Rio de Janeiro City. Arq Neuropsiquiatr 60: 1051, 2002.

122. Carvalho A, Sant'anna G, Santos CC, Frulhetti IP, Leon AS and Quírico-Santos T: Determination of autoantibody for myelin antigens in the serum of patients HLA-DQB1*0602 with multiple sclerosis. Arq Neuropsiquiatr 61: 968-973, 2003.

123. Alves-Leon SV, Papais-Alvarenga R, Magalhães M, Thuler LC, Fernandez $\mathrm{Y}$ and Fernandez O: Ethnicity-dependent association of HLA DRB1-DQA1-DQB1 alleles in Brazilian multiple sclerosis patients. Acta Neurol Scand 115: 306-311, 2007.

124. Brum DG, Barreira AA, Louzada P Jr, Mendes CT Jr and Donadi E: Association of the HLA-DRB1*15 allele group and DRB1*1501 and DRB1*1503 alleles with multiple sclerosis in White and Mulatto samples from Brazil. J Neuroimmunol 189: 118-124, 2007

125. Kaimen-Maciel DR, Reiche EM, Borelli A, et al: HLA-DRB1* allele-associated genetic susceptibility and protection against multiple sclerosis in Brazilian patients. Mol Med Rep 2: 993-998, 2009.

126. Vasconcelos CC, Fernández O, Leyva L, Thuler LC and Alvarenga RM: Does the DRB1*1501 allele confer more severe and faster progression in primary progressive multiple sclerosis patients? HLA in primary progressive multiple sclerosis. J Neuroimmunol 214: 101-103, 2009. 